\title{
Community awareness about malaria, its treatment and mosquito vector in rural highlands of central Ethiopia
}

\author{
Mengistu Legesse ${ }^{1}$, Wakgari Deressa ${ }^{2}$
}

\begin{abstract}
Background: Despite the rapid expansion of malaria into highland areas of Ethiopia and the movement of malaria inexperienced people to endemic areas, there is no enough information about how highland communities perceive malaria.
\end{abstract}

Objective: To assess communities' awareness of malaria and its mosquito vector in highland rural communities of central Ethiopia.

Methods: A community-based cross-sectional survey involved 770 heads of household was conducted during September 2005 to February 2006 in nine peasant associations of five purposely selected districts in highland areas where malaria has been recently introduced, or currently free from the disease.

Results: The majority of the study participants knew that malaria is a serious disease that can attack all age groups of a population (81.0\%). A considerable number of individuals, 357 (47.5\%) responded that they visited malarious area and about $50 \%$ of these individuals reported that they or their families had got the disease. A large proportion of participants (81.6\%) mentioned that mosquito transmits malaria through biting (91.6\%), while 176 (42.6\%) individuals are aware that mosquitoes bite during night. Participants from Sheno, Muka Turi and Sululita areas were found to better in associating the cause of malaria with mosquito bites than those participants from Ginchi and Holeta areas ( $p<$ 0.05). In contrast, participants from Ginchi area were found to better in identifying the common signs/symptoms of malaria and recommending modern antimalarial drug for treatment than participants from other localities $(\mathrm{p}<0.05)$. Some of the respondents believed that mosquito bites or landing can be prevented using various methods like mosquito net, eating or keeping garlic in pocket, while more than half (67.1\%) of the participants had no information about preventive methods of mosquito bites.

Conclusion: Communities residing in the highland of the present study areas were aware that malaria is a serious disease. However, they had no clear information about its cause, mode of transmission and preventive methods. Hence, emphasis should be given to increase community awareness through implementation of appropriate health education program for prevention and control of the disease from expanding into highland areas of Ethiopia. [Ethiop.J.Health Dev. 2009;23(1):40-47]

\section{Introduction}

Highland malaria epidemic has repeatedly become one of the serious public health problems in many east African countries like Ethiopia, Kenya, Uganda and Tanzania particularly since the late 1980 s mainly due to climatic change (1) and other factors related to changes in land use, drug resistance, migration of non-immune people, inadequate health facilities (2, 3). In Ethiopia, malaria was previously considered a major public health threat to people living in lowland areas of the country (4). In recent years, however, the disease has been expanding its extensive geographic coverage, and is increasingly recognized as a major health problem in midlands (temperate) and even in some highland areas of the country $(1,3,5)$. In addition, non-immune people living in highland areas frequently move to malaria endemic areas for various purposes such as settlement, search for fertile lands, seasonal migration of pastoralists, and those seeking job opportunities $(6,7)$.

Many studies have addressed that lack of community awareness about malaria could contribute to the spread of the disease in part, hinder control strategy and increase risk of exposure to the disease $(3,8,9)$. Despite the rapid expansion of malaria into highland areas of Ethiopia and the movement of malaria experienced people to endemic areas, studies pertaining to knowledge, attitude and perception about malaria have only focused on communities living in malaria endemic areas $(10,11)$. There is no data on the basic awareness about how malaria is transmitted and how people protect themselves from the disease among communities living in the highlands of Ethiopia. Therefore, in this study an effort was made to assess community awareness of malaria, its cause and mode of transmission, prevention and treatment as well as its mosquito vector in highland rural communities of west and north Shewa Zones, central Ethiopia.

\section{Methods}

Study Areas and Population: A community-based cross-sectional survey was conducted during September 2005 to February 2006 to assess awareness of malaria, its mosquito vector and treatment practice in nine peasant associations of five purposely selected districts in central highlands of west and north Shewa Zones, Oromiya Regional State. The study peasant associations included communities living in Holeta and Ginchi District about

${ }^{1}$ Aklilu Lemma Institute of Pathobiology, Addis Ababa University, P. O. Box 1176, Fax: 00251-1-2755296, e-mail: dlegessem@yahoo.com, Addis Ababa, Ethiopia; ${ }^{2}$ Department of Community Health, Faculty of Medicine, Addis Ababa University P. O. Box 9086, Addis Ababa, Ethiopia 
30- $110 \mathrm{~km}$ west of Addis Ababa, Sululita and Muke Turi districts about 15, and $78 \mathrm{~km}$ north of Addis Ababa respectively, and Sheno District about $87 \mathrm{~km}$ to the north east of Addis Ababa.

Peasant associations included in the study were ElalaGojo, Worka-Worebo, Beshi-Kiltu, Galessa-Kota Geshri, Gora-Ketaba, Gora-Worto, Woserbi, AdadiMeto and Mogora-Gara Dega. Elala-Gojo peasant association is found around Holeta town, $30 \mathrm{~km}$ to the west of Addis Ababa at an altitude of 2507 meters above sea level (measured using Global Position System, GPS). This peasant association is in close proximity to areas where malaria has recently been occurring. WorkaWorebo and Beshi-Kiltu peasant associations are found at $7 \mathrm{~km}$ and $32 \mathrm{~km}$ respectively, south east of Ginchi town, about $110 \mathrm{~km}$ to the south west of Addis Ababa. The area is located at altitudes between 2236 and 2246 meters above sea level. According to information obtained form the District Health Office and the local inhabitants, a malaria epidemic was occurred in 1998, a disease not previously common in these areas. GalessaKota Geshri is a peasant association about $18 \mathrm{~km}$ north west of Ginchi town and located at an altitude of 3022 meters above sea level. This peasant association is bordering Gare Arera peasant association where a malaria epidemic was occurred in 1998. Gora-Ketaba and Gora-Worto peasant associations are located around Muka Turi town, $78 \mathrm{~km}$ north of Addis Ababa, at altitudes between 2651 and 2682 meters above sea level. The area is in close proximity to malarious localities to the north. Woserbi peasant association is found in Sululita District $10 \mathrm{~km}$ to the north of Addis Ababa. The area is situated at an approximate altitude of 2740 meters above sea level. People living in this area usually move to malaria endemic areas like east Shewa Zone for temporary job opportunities (especially collecting crops). Adadi-Meto and Mogora-Gara Dega peasant associations are located around Sheno town about $80 \mathrm{~km}$ to the north east of Addis Ababa in north Shewa Zone. The area is located at altitudes range from 2835 to 2880 meters above sea level.

Using the above information, selection of the study peasant associations was based on the following criteria: being assumed to be highland areas where malaria had not occurred or recently appeared, closer to malarious areas, non-immune populations living in those peasant associations frequently move to malaria endemic areas for various purposes such as search for seasonal job opportunities and grassland, and accessibility of the areas to the main road.

Sample Size Estimation: Because there was no previous information on the level of community awareness in the study areas, EPI INFO 2002 software package formula for estimations in population surveys (11) was used. Thus, a minimum of 720 participants (20\% compensation for non-respondents) were included in the study.

Selection of Study Participants and Data Collection: Prior to data collection, the research team in collaboration with the respective health offices of each district identified the total number of highland peasant associations in that district which fulfilled the above stated criteria. Then, two to three peasant associations were picked using a lottery method from each district taking logistic problem into consideration, although many peasant associations were identified as eligible for inclusion. Based on the number of households in the selected peasant association, the estimated sample size (720) was proportionally distributed to the selected nine peasant associations. Each peasant association was stratified into manageable villages, certain villages were randomly selected and the number of houses in the selected villages was listed. Based on the required sample size from that peasant association, houses were systematically selected from the villages. One person per household (head of the household, male or female) was interviewed about malaria, its mode of transmission, prevention and treatment using pre-tested structured questionnaires. The participants were interviewed by trained data collectors using the local language (Afaan Oromo) after explaining the aim of the study.

Data Analysis: Data were analyzed using SPSS, Version 10.0. Chi-square test was used to determine difference in the proportion of awareness between the peasant associations from various districts as well as between women and men participants. Differences were considered significant at p-value less than 0.05 .

Ethical Consideration: Ethical clearance was secured from the Ethical Clearance Committee of Aklilu Lemma Institute of Pathobiology, Addis Ababa University before the implementation of the study. Informed verbal consent was also obtained from the study participants before interview. At the end of the interview, information about malaria, its mode of transmission, methods of prevention and treatment were explained to the study participants.

\section{Results}

A total of 770 individuals participated in the study giving a response rate exceeded $100 \%$. Of these, 436 were males with age ranging from 20 to 100 years (mean 45.4) and 334 were females, age between 18 and 80 years (mean 40.1). Table 1 shows the socio-demographic characteristics of the study participants. The majority (91.2\%) of the participants were from Oromo ethnic group, Orthodox followers (94.8\%) and farmers (96.8\%). More than half (69.2\%) of the respondents were illiterate. 
Table 1: Socio-demographic characteristics of the study participants, central highland areas of Shewa, September 2005 to February 2006

\begin{tabular}{lc}
\hline Variables & Number (\%) \\
\hline Sex & $436(56.6)$ \\
Male & $334(43.4)$ \\
Female & \\
Age & $174(22.6)$ \\
$18-29$ & $173(22.5)$ \\
$30-39$ & $164(21.3)$ \\
$40-49$ & $109(14.2)$ \\
$50-59$ & $150(19.5)$ \\
$60+$ & \\
Ethnicity & $702(91.2)$ \\
Oromo & $29(3.8)$ \\
Amhara & $38(4.9)$ \\
Gurage & $1(0.1)$ \\
Walayta & \\
Religion & $730(94.8)$ \\
Orthodox & $6(0.8)$ \\
Muslim & $34(4.4)$ \\
Protestant & \\
Occupation & $745(96.8)$ \\
Farmer & $14(1.8)$ \\
Merchant & $11(1.4)$ \\
Other & \\
Educational status & $533(69.2)$ \\
Illiterate & $51(6.6)$ \\
Read and write & $149(19.4)$ \\
Primary & $37(4.8)$ \\
Secondary &
\end{tabular}

Table 2 depicts variables used to collect community awareness about public health importance, cause and mode of transmission of malaria. Among the total of 770 participants, 751(97.5\%) responded that they have heard about malaria. The proportion of male participants who heard about malaria was higher than that of female participants $(p<0.05)$. Among the individuals who heard about malaria, 357 (47.5\%) responded that they visited malaria area once or more. Over $50 \%$ of these individuals reported that they or their families had got malaria.

Among the respondents who heard about malaria, 90 (12\%) individuals said that malaria can be transmitted from person to person. Of these, 40 (44.3\%) mentioned that the infection is transmitted through mosquito bites. High proportion of female participants had no information whether malaria can be transmitted from person to person compared to male participants (53.3\% vs $28.4 \%$, $p<0.05)$. Age or educational status was not significantly associated with the level of basic awareness (how malaria is caused, transmitted or prevented). Other misconceptions including body contacts (like sweat, sharing cloth, saliva, vomit), breathing or through sharing meals with a malaria patient were also suggested as ways of malaria transmission. The majority of

Table 2: Knowledge about cause and mode of transmission of malaria, central highland areas of Shewa, September 2005 to February 2006

\begin{tabular}{|c|c|c|c|}
\hline \multirow[b]{2}{*}{ Variables } & \multicolumn{3}{|c|}{ Number of respondents (\%) } \\
\hline & Male $n=436$ & $\begin{array}{l}\text { Female } n= \\
334\end{array}$ & Total $n=770$ \\
\hline \multicolumn{4}{|l|}{ Heard about malaria } \\
\hline Yes & $430(98.6)$ & $321(96.1)$ & $751(97.5)$ \\
\hline No & $6(1.4)$ & $13(3.9)$ & $19(2.5)$ \\
\hline \multicolumn{4}{|l|}{ Visited/lived in malaria area } \\
\hline Yes & $241(56.1)$ & $116(36.1)$ & 357 (47.5) \\
\hline No & $189(43.9)$ & $205(63.9)$ & $394(52.5)$ \\
\hline \multicolumn{4}{|l|}{ Sick from malaria $(n=357)$} \\
\hline Yes & $129(53.5)$ & $62(53.4)$ & 191(53.5) \\
\hline No & $112(46.5)$ & $54(46.6)$ & $166(46.5)$ \\
\hline \multicolumn{4}{|l|}{ Malaria transmits from person to person } \\
\hline Yes & $61(14.2)$ & $29(9.0)$ & $90(12.0)$ \\
\hline No & $247(57.4)$ & $121(37.7)$ & $368(49.0)$ \\
\hline Do not know & $122(28.4)$ & $171(53.3)$ & $293(39.0)$ \\
\hline \multicolumn{4}{|l|}{ Mode of transmission } \\
\hline Mosquito bite & $27(44.3)$ & $13(44.8)$ & $40(44.3)$ \\
\hline Contact (sweat, cloth, saliva, vomit, sleep/eating with patient) & $22(36.1)$ & $11(37.9)$ & $33(36.7)$ \\
\hline Breathing & $22(36.1)$ & $9(31.0)$ & $31(34.4)$ \\
\hline Do not know & $6(9.8)$ & $4(13.8)$ & $10(11.1)$ \\
\hline \multicolumn{4}{|l|}{ Cause of malaria } \\
\hline Mosquito bite & $98(22.8)$ & $34(10.6)$ & 132(17.6) \\
\hline Drinking river/dirty water & $32(7.4)$ & $9(2.8)$ & $41(5.5)$ \\
\hline Eating fresh maize & $3(0.7)$ & $0(0)$ & $3(.4)$ \\
\hline Bad air (cold/hot) & $12(2.7)$ & $7(2.2)$ & $19(2.5)$ \\
\hline starvation/thirst & $16(3.7)$ & $8(2.5)$ & $24(3.2)$ \\
\hline Seating under a tree & $9(2.1)$ & $3(0.9)$ & $12(1.6)$ \\
\hline Eating food outdoor & $4(0.9)$ & $1(0.3)$ & $5(0.7)$ \\
\hline Somebody/something sleeping with you during night & $8(1.9)$ & $3(0.9)$ & $11(1.5)$ \\
\hline Somebody calls you during night & $9(2.1)$ & $2(.6)$ & $11(1.5)$ \\
\hline Do not know & $249(57.9)$ & $244(76.0)$ & $493(65.6)$ \\
\hline
\end{tabular}


participants (81\%) knew that malaria could attack both males and females as well as all age groups. Only 132 (17.6\%) of the study participants mentioned that mosquito bites could cause malaria, while others associated the disease with drinking dirty water, eating fresh maize, exposure to bad air , starvation /thirst and eating food outdoor. Few respondents also believed that sleeping with somebody or something like cat or dog in a dream, and being called by somebody in a dream could cause malaria.

Table 3 presents communities' awareness about signs/ symptoms, treatment and prevention of malaria in the study areas. More than half (54.3\%) of the study participants reported that shivering is one of the most common symptoms of malaria while others mentioned symptoms like cold, headache, abdominal discomfort, back pain and loss of appetite.

Table 3: Knowledge about signs/ symptoms, treatment and prevention of malaria, Central highlands of Shewa, September 2005 - February 2006

\begin{tabular}{|c|c|c|c|}
\hline \multirow[b]{2}{*}{ Variables } & \multicolumn{3}{|c|}{ Number of respondents (\%) } \\
\hline & $\begin{array}{l}\text { Male } \\
\mathrm{N}=430\end{array}$ & $\begin{array}{l}\text { Female } \\
\mathrm{N}=321\end{array}$ & $\begin{array}{l}\text { Total } \\
\mathrm{N}=751\end{array}$ \\
\hline \multicolumn{4}{|l|}{ Signs/symptoms of malaria } \\
\hline Shivering & $228(53.0)$ & $180(56.1)$ & 408(54.3) \\
\hline Cold & $51(11.9)$ & $22(6.9)$ & $73(9.7)$ \\
\hline Headache & $87(20.2)$ & $35(10.9)$ & $122(16.2)$ \\
\hline Abdominal discomfort, diarrhea, vomiting & $36(8.4)$ & $17(5.3)$ & $53(7.1)$ \\
\hline Back pain, weakness & $47(10.9)$ & $22(6.9)$ & $69(9.2)$ \\
\hline Lose of appetite & $20(4.7)$ & $16(5.0)$ & $36(4.8)$ \\
\hline Sweat, fever & $41(9.5)$ & $8(2.5)$ & $49(6.5)$ \\
\hline Other (cough, yellow urine, fatigue, thirst) & 13(3.0) & $9(2.9)$ & $22(2.9)$ \\
\hline Do not know & $123(28.6)$ & $149(46.4)$ & $272(36.2)$ \\
\hline \multicolumn{4}{|l|}{ Treatment of malaria } \\
\hline Modern antimalarial drug & $372(86.5)$ & $241(75.1)$ & 613(81.6) \\
\hline Garlic and butter & $127(29.5)$ & $83(25.9)$ & $210(28.0)$ \\
\hline Black goat & $10(2.3)$ & $1(0.3)$ & $11(1.5)$ \\
\hline Dried cow's dung & $8(1.9)$ & $7(2.2)$ & $15(2.0)$ \\
\hline Traditional healer & $63(14.6)$ & $48(15.0)$ & $111(14.8)$ \\
\hline Other (honey, meat, egg) & $34(7.9)$ & $17(5.3)$ & $51(6.8)$ \\
\hline Do not know & $23(5.3)$ & $45(14.0)$ & $68(9.1)$ \\
\hline \multicolumn{4}{|l|}{ Best treatment $(n=208, M=135 F=73)$} \\
\hline Modern antimalarial drug & $85(62.9)$ & $47(64.4)$ & 132(63.5) \\
\hline Traditional medicine & $47(34.8)$ & $24(32.9)$ & $71(34.1)$ \\
\hline Do not know & $3(2.2)$ & $2(2.7)$ & $5(2.4)$ \\
\hline \multicolumn{4}{|l|}{ Preventive methods } \\
\hline Antimalarial drug /treatment & $52(12.1)$ & $20(6.2)$ & $72(9.6)$ \\
\hline Garlic & $126(29.3)$ & $75(23.4)$ & $201(26.8)$ \\
\hline Tobacco & $33(7.7)$ & $9(2.8)$ & $42(5.6)$ \\
\hline Agober & $10(2.3)$ & $3(0.9)$ & $13(1.7)$ \\
\hline Environmental/personal hygiene & 16(3.7) & $4(1.2)$ & $20(2.7)$ \\
\hline Spray & $2(0.5)$ & 1(0.3) & $3(0.4)$ \\
\hline Avoiding stagnant water & $4(0.9)$ & $0(0)$ & $4(0.5)$ \\
\hline Other (do not eat maize, do not swim/drink stagnant water) & $21(4.9)$ & $8(2.5)$ & $29(3.9)$ \\
\hline Do not know & $214(49.8)$ & 214(66.7) & $428(57.0)$ \\
\hline
\end{tabular}

Regarding the treatment of malaria, majority of the participants (81.6\%) reported modern antimalarial drugs although about $28 \%$ of them identified the use of garlic mixed with a butter stored for about 7 years as effective malaria treatment. Few participants also mentioned that eating/drinking blood or stomach contents of black goat as effective treatment for malaria while others said smoking or drinking dried cow's dung stored for about 7 years. Among those respondents who mentioned the use of both traditional and modern antimalarial drugs, 132 (63.5\%) stated that modern antimalarial drugs are more effective than traditional treatment, while $71(34.1 \%)$ of the participants mentioned that traditional treatment is more effective than modern antimalarial drugs.
Few of the participants mentioned that malaria could be prevented using antimalarial drug (9.6\%) or mosquito net (1.7\%) while about $57 \%$ of the participants reported that they had no information about preventive methods of malaria.

An attempt was also made to assess community awareness about malaria season and factors underlying seasonal variation. About 51\%, of the participants said that malaria is more common from September to November. When asked why malaria is common during the reported months, 67(17.5\%) individuals mentioned the abundance of mosquito breeding while others 
suggested various reasons like cold, hot, eating fresh maize, stagnant water and smell of various flowers.

Community awareness regarding the vector of malaria was also assessed (Table 4). The majority of the participants (73.6\%) reported that they heard about mosquito. The proportion of males who heard about mosquito was higher than the proportion of females (79.3\% vs 66.0\% p < 0.05). Regarding the breeding site of mosquito, $31.3 \%$ of the respondents mentioned stagnant water while others mentioned dirty areas, water, forest, under stone, dry area, or mud as possible sites.

Table 4: Knowledge about malaria vector, central highlands of Shewa, September 2005 to February 2006

\begin{tabular}{|c|c|c|c|}
\hline \multirow[b]{2}{*}{ Variables } & \multicolumn{3}{|c|}{ Number of respondents (\%) } \\
\hline & $\begin{array}{l}\text { Male } \\
n=430\end{array}$ & $\begin{array}{l}\text { Female } \\
n=321\end{array}$ & $\begin{array}{l}\text { Total } \\
\mathrm{n}=751\end{array}$ \\
\hline \multicolumn{4}{|l|}{ Heard about mosquito } \\
\hline Yes & $341(79.3)$ & 212(66.0) & $553(73.6)$ \\
\hline No & $89(20.7)$ & 109(34.0) & 198(26.4) \\
\hline \multicolumn{4}{|l|}{ Mosquito breeds $(n=553, M=341, F=212)$} \\
\hline Stagnant water, dirty water & $150(44.0)$ & $50(23.6)$ & $200(36.2)$ \\
\hline River water & $40(11.7)$ & 23(10.9) & $63(11.4)$ \\
\hline Other (under stone, dry area, mud, maize, well, house) & $20(5.9)$ & $8(3.7)$ & $28(5.1)$ \\
\hline Do not know & $131(38.4)$ & $131(61.7)$ & $262(47.4)$ \\
\hline \multicolumn{4}{|l|}{ Role of mosquito $(n=553, M=341, F=212)$} \\
\hline Transmits malaria & 293(85.9) & 158(74.5) & 451(81.6) \\
\hline Causes a disease & $20(5.9)$ & $28(13.2)$ & $48(8.7)$ \\
\hline \multicolumn{4}{|l|}{ Mosquito transmits malaria } \\
\hline Biting & 271(92.5) & $142(89.9)$ & 413(91.6) \\
\hline Landing on you, Contaminate food/water & $24(8.2)$ & 21(13.3) & $45(10.0)$ \\
\hline Do not know & $11(3.8)$ & $15(9.5)$ & $26(5.8)$ \\
\hline \multicolumn{4}{|l|}{ Mosquito bites/landing } \\
\hline Night time & 128(47.2) & 48(33.8) & $176(42.6)$ \\
\hline Day time & $45(16.2)$ & $22(15.5)$ & $67(16.2)$ \\
\hline Any time & $79(29.2)$ & $45(31.6)$ & $124(30.0)$ \\
\hline Do not know & $25(9.2)$ & $37(26.1)$ & $62(15.0)$ \\
\hline \multicolumn{4}{|l|}{ Mosquito biting is preventable } \\
\hline Yes & $90(32.5)$ & $36(23.7)$ & $126(29.4)$ \\
\hline No & $14(5.1)$ & $1(0.7)$ & $15(3.5)$ \\
\hline Do not know & $173(62.5)$ & $115(75.7)$ & $288(67.1)$ \\
\hline \multicolumn{4}{|l|}{ Preventive methods } \\
\hline Bed net & $67(74.4)$ & 28(80.0) & $95(76.0)$ \\
\hline Garlic & $11(12.2)$ & $0(0)$ & 11(8.8) \\
\hline Spray & $8(8.9)$ & $3(8.6)$ & 11(8.8) \\
\hline Other (personal hygiene, closing door, tobacco, cloth) & $15(16.7)$ & $7(19.4)$ & $22(17.5)$ \\
\hline Do not know & $2(2.2)$ & $0(0)$ & $(1.6)$ \\
\hline
\end{tabular}

Among the respondents who heard about mosquito, 451 (81.6\%) individuals mentioned that mosquito transmits malaria. Of these individuals, the majority (91.6\%) mentioned that mosquito transmits malaria through biting at night (42.6\%), day time (16.2\%) and anytime (30.0\%). Some of the respondents believed that mosquito bites or landing can be prevented using various methods like mosquito net, eating or keeping garlic in pocket, covering the whole body with cloth during the night and spraying the house/rooms with insecticides.

Table 5 shows knowledge of communities about the cause, mode of transmission, symptoms, treatment and prevention of malaria in the various studied localities. Although the majority of the participants from various localities had heard about malaria, participants from
Sheno, Muka Turi and Sululita areas were found to better in identifying the cause of malaria than those participants from Ginchi and Holeta areas ( $\mathrm{p}<0.05)$. In contrast, participants from Ginchi area were found to be better in identifying the common signs and symptoms of malaria than participants from other localities ( $<<0.05)$. Regarding the treatment of malaria, higher proportion of participants from Ginchi and Holeta reported modern antimalarial drug than participants from other localities $(\mathrm{p}<0.05)$. Majority of the participants from Ginchi and Holeta had heard about mosquito vector compared to participants from other localities $(\mathrm{p}<0.05)$. On the other hand, it seems that participants from the various localities had similar information that mosquito transmits malaria through biting ( $>00.05)$. 
Table 5: Knowledge of communities about cause, signs/ symptoms, treatment, prevention of malaria, and mosquito in the various studied localities, central highlands of Shewa, September 2005 to February 2006 variables Localities and Number of Respondents

\begin{tabular}{|c|c|c|c|c|c|}
\hline & $\begin{array}{l}\text { Ginchi } \\
n=321\end{array}$ & $\begin{array}{l}\text { Holeta } \\
n=147\end{array}$ & $\begin{array}{l}\text { Sululita } \\
n=50\end{array}$ & $\begin{array}{l}\text { Muka Tur } \\
\mathrm{n}=175\end{array}$ & $\begin{array}{l}\text { Sheno } \\
n=77\end{array}$ \\
\hline \multicolumn{6}{|l|}{ Heard about malaria } \\
\hline Yes & $308(96 \%)$ & $146(99.3 \%)$ & $49(98 \%)$ & $173(98.9 \%)$ & $75(97.4 \%)$ \\
\hline No & $13(4 \%)$ & $1(0.7 \%)$ & $1(2 \%)$ & $2(1.1 \%)$ & $2(2.6 \%)$ \\
\hline \multicolumn{6}{|l|}{ Cause of malaria } \\
\hline Mosquito bite & $23(7.5 \%)$ & $18(12.3 \%)$ & $9(18.4 \%)$ & $51(29.5 \%)$ & $31(41.3 \%)$ \\
\hline Other & $41(13.3 \%)$ & $8(5.5 \%)$ & $10(20.4 \%)$ & $50(28.9 \%)$ & $17(22.7 \%)$ \\
\hline Do not know & $244(79.2 \%)$ & $120(82.2 \%)$ & $30(61.2 \%)$ & $72(41.1 \%)$ & $27(36 \%)$ \\
\hline \multicolumn{6}{|l|}{ Signs/Symptoms of Malaria } \\
\hline One or more symptoms mentioned & $234(76 \%)$ & $80(54.8 \%)$ & $27(55.1 \%)$ & $93(53.8 \%)$ & $45(60 \%)$ \\
\hline Do not know & $74(24.0 \%)$ & $66(45.2 \%)$ & $22(44.9 \%)$ & $80(46.2 \%)$ & $30(40 \%)$ \\
\hline \multicolumn{6}{|l|}{ Treatment of Malaria } \\
\hline Modern Antimalarial drug & 289(93.8\%) & $131(89.7 \%)$ & $25(51.0 \%)$ & $125(72.3 \%)$ & $43(57.3 \%)$ \\
\hline Traditional Medicine & $53(17.2 \%)$ & $42(28.8 \%)$ & $26(53.1 \%)$ & $118(68.2 \%)$ & $39(52 \%)$ \\
\hline Do not know & $10(3.2 \%)$ & $10(6.8 \%)$ & $13(26.5 \%)$ & $21(12.1 \%)$ & $14(18.7 \%)$ \\
\hline \multicolumn{6}{|l|}{ Heard about mosquito } \\
\hline Yes & $239(77.6 \%)$ & $127(87 \%)$ & $31(63.3 \%)$ & $105(60.7 \%)$ & $51(68 \%)$ \\
\hline No & $69(22.4 \%)$ & $19(13 \%)$ & $18(36.7 \%)$ & $68(39.3 \%)$ & $24(32 \%)$ \\
\hline \multicolumn{6}{|l|}{ Role of mosquito } \\
\hline Transmits malaria & $189(79.1 \%)$ & $111(87.4 \%)$ & $22(71 \%)$ & $86(81.9 \%)$ & $43(84.3 \%)$ \\
\hline Causes other diseases & $21(8.8 \%)$ & $10(7.9 \%)$ & $5(16.1 \%)$ & $9(8.6 \%)$ & $3(5.9 \%)$ \\
\hline Do not know & $29(12.1 \%)$ & $6(4.7 \%)$ & $4(12.9 \%)$ & $10(9.5 \%)$ & $5(9.8 \%)$ \\
\hline \multicolumn{6}{|l|}{ Mosquito transmits malaria } \\
\hline During biting & 177(93.7\%) & $101(91 \%)$ & $19(86.4 \%)$ & $79(91.9 \%)$ & $37(86.1 \%)$ \\
\hline Other & $23(12.2 \%)$ & $6(5.4 \%)$ & $2(9.1 \%)$ & $9(10.5 \%)$ & $5(11.6 \%)$ \\
\hline Do not know & $8(4.2 \%)$ & $9(8.1 \%)$ & $3(13.6 \%)$ & $4(4.7 \%)$ & $2(4.7 \%)$ \\
\hline \multicolumn{6}{|c|}{ Preventive methods of mosquito bites } \\
\hline Bed net, spray & $37(20.9 \%)$ & $39(38.6 \%)$ & $3(15.8 \%)$ & $15(19.0 \%)$ & $12(32.4 \%)$ \\
\hline Other & $8(4.5 \%)$ & $8(7.9 \%)$ & $2(10.5 \%)$ & $11(13.9 \%)$ & $4(10.8 \%)$ \\
\hline Do not know & $0(0 \%)$ & $0(0 \%)$ & $1(5.3 \%)$ & $1(1.3 \%)$ & $0(0 \%)$ \\
\hline
\end{tabular}

\section{Discussion}

In this study, we assessed community awareness about cause, mode of transmission, symptoms, treatment, and prevention of malaria as well as knowledge of mosquito vector in communities living in central highlands of Ethiopia previously known Shewa province. The results indicated that almost all the study participants from the various peasant associations knew that malaria is a serious disease for all age groups. Most of the participants have also mentioned some of the common signs and symptoms of malaria and modern antimalarial drugs as the best treatment for malaria though their level of knowledge in identifying the symptoms was not as high as that found in the malaria endemic areas of the country $(11,12)$.

On the other hand, the study indicated that the majority of people living in the study areas had little or no information regarding the cause, mode of transmission and preventive methods of malaria. Very low proportion of the participants was aware that malaria could be transmitted from person-to-person through mosquito bites. Though mosquito bite was implicated as a cause of malaria, the aetiologic agent of malaria was not suggested as people usually incriminate mosquitoes as the causative agents of malaria $(13,14,15)$. Similar to previous reports from elsewhere $(16,17,18)$, a considerable number of the participants have also associated the cause of malaria with various factors such as exposure to bad air, starvation/thirst, or evil sprit like sleeping with something like a person or animals like cat, dog or bird and call by somebody in a dream. These wrong beliefs could hamper prevention and control of the disease.

The results also indicated lack of a clear knowledge about the spread of the disease, which has been observed in several studies in malarious areas $(11,19)$. Among those individuals who knew that malaria could be transmitted from person-to-person, a considerable number of them believed that the disease could be transmitted from a malaria patient to another person in several ways. These include contact with patient's sweat, cloth, vomit, breathing or eating with the patient. However, when asked about the role of the mosquito, a large proportion of respondents mentioned that it transmits malaria through biting which is comparable to the knowledge of communities in malarious areas of Ethiopia (12).

Since people living in the study areas especially, males often move to malaria endemic areas such as Modjo and 
Bacho for temporary job opportunities like harvesting during high malaria seasons (September to December), their awareness of malaria season was assessed. Interestingly, about half of the participants had awareness about the peak malaria transmission season (September to November) in the endemic areas though they had no clear information why the disease is common during those months.

Early diagnosis and effective treatment with appropriate antimalarial drugs are the major strategies to reduce morbidity and mortality due to malaria (20). This could be hindered either by lack of knowledge about the cause of malaria, its effective treatment or community beliefs of the disease $(18,19,21,22,23)$, which leads to many deaths. In this study, differences in knowledge about the cause, signs/symptoms and treatment of malaria as well as mosquito vector were compared among the participants from various localities. Participants from the epidemic-prone (Ginchi and Holeta areas) were found to be better in identifying signs/symptoms of malaria, considering modern antimalarial drugs as effective for the treatment of the disease and choosing of chemoprophylaxis, bed net, spray and avoiding stagnant water as preventive methods of malaria which is in agreement with previous studies done elsewhere $(11,12$, 13). On the other hand, practice of using traditional medicines such as garlic, butter, tobacco and other remedy for the treatment of malaria as well as for preventive mechanisms was highly reflected by respondents from Sululita, Muka Turi and Sheno areas. About $34 \%$ of the participants even believed that traditional medicine is more powerful than modern antimalarial drugs as complete cure for malaria. This could have a considerable impact on the treatment seeking behaviour of the communities in the study areas.

In conclusion, this study revealed that communities of the study areas frequently visit malarious areas for different purposes. Nevertheless, they have no sufficient information regarding the mode of malaria transmission, its effective treatment and protective methods despite a high level of awareness about the public health importance of the disease. Hence, emphasis should be given to health education programs for prevention and control of the expansion of the disease into highland or epidemic-prone areas of Ethiopia. Because of financial constraints, our study was restricted to very few communities in highland localities in central Shewa. Undertaking such studies in various highland areas of the country would be useful for the control of the disease.

\section{Acknowledgments}

The authors would like to acknowledge community leaders and the study participants for their unfailing cooperation during the survey. This study was financially supported by the Ethiopian Science and Technology Agency.

\section{References}

1 .

Kiszewski, AE, Teklehaimanot A. A review of the clinical and epidemiologic burdens of epidemic malaria. Am. J. Trop. Med.Hyg. 2004;71:128-35.

$2 . \quad$ Lindblade KA, Walker ED, Wilson ML. Early warning of malaria epidemics in African highlands using Anopheles (Diptera: Culicidae) indoor resting density. J. Med. Entomol. 2000;37:664-74.

3. Deressa W, Olana D, Chibsa S. Community participation in malaria epidemic control in highland areas of southern Oromia, Ethiopia. Ethiop. J. Health Dev. 2005: 19: 3-10.

4.

Tulu AN. Malaria. In: The ecology of health and disease in Ethiopia (eds). Zein AZ, Kloos W H. Westview press, Colarado 1993;341-52.

5. Woyessa A, Gebre-Michael T, Ali A, Daniel K. Malaria in Addis Ababa and its environs: assessment of magnitude and distribution. Ethiop. J. Health Dev. 2002;16:147-55.

6. Nega A, Meskal FH. Population migration and malaria transmission in Ethiopia. In : Malaria and economic development in Africa, a cross-sectional approach, American Association for the advancement of Science. Washington D.C. 1991; PP. 181-9.

7. Abeku TA, Van Oortmarssen GJ, Borsboom G, De Vlas SJ, Habbema JDF. Spatial and temporal variations of malaria epidemic risk in Ethiopia: factor involved and implications. Act Trop. 2003;87:331-40.

8. Collins KA, Samuel KD, Edwin AA, Kwadwo A, Korum J, Francis KN. Malaria related beliefs and behaviour in southern Ghana: implication for treatment, prevention and control. Trop. Med. Int. Health 1997;2:488-99.

9. Yadav SP, Tyagi BK, Ramanath T. Knowledge, attitude and practice towards malaria in rural communities of the epidemic prone Thar Desert, northwestern India. J. Commun. Dis. 1999;3:127-36.

10. Yeneneh H, Gyorkos TW, Joseph L, Pickering J, Tedla S. Antimalarial drug utilization by women in Ethiopia: a knowledge, attitudes-practice study. Bull. WHO 1993;71:763-72.

11. Deressa W, Ali A, Enquoselassie F. Knowledge, attitude and practice about malaria, the mosquito and antimalarial drugs in a rural community. Ethiop. J. Health Dev. 2003;17:99-104.

12.

Jimma D, Tesfaye G, Deressa W, Woyessa A, Kebede D, Alamirew D. Baseline survey for the implementation of insecticide treated mosquito nets in malaria control in Ethiopia. Ethiop J. Health Dev. 2005;19:16-23.

13. Karanja DM, Alaii J, Abok K, Adungo NI, Githeko AK, Seroney I, et al. Knowledge and attitude to malaria control and acceptability of permethrin impregnanated sisal curtains. East Afr.

Ethiop.J.Health Dev. 2009;23(1) 
Med. J. 1999;76:42-6.

14.

Govere J, Durrheim D, la Grange K,

Mabuza A, Booman M. Community knowledge and perception about malaria and practices influencing malaria control in Mpumalanga province, South Africa. South Afr. Med. J. 2000;90:611-6.

15.

Okrah J, Traore C, Pale A, Sommerfeld, J, Muller O. Community factors associated with malaria prevention by mosquito nets: an exploratory study in rural Burkina Faso. Trop. Med. Int. Health 2002;7:240-48.

16. Ramakrishna J, Brieger WR, Adeniyi JD. Treatment of malaria and febrile convulsions: an educational diagnosis of Yoruba beliefs. Int. Q. Commun. Health. Educat. 1988;9:305-19.

17. Mwenesi HA, Harphan T, Marsh K, Snow RW. Perceptions of symptoms of severe childhood malaria among Mujikenda and Luo residents of coastal Kenya. J. Biosocial Scie. 1995;27:235-44.

18. Makemba AM, Winch PJ, Makame VM, Mehl GL, Premji Z, Minjas JN, Shiff CJ. Treatment practice for degedege, a locally recognized febrile illness and implications for strategies to decrease mortality from severe malaria in Bagamoyo District, Tanzania. Trop Med Int. Health 1996;1:305-13.
19.

Singh N, Singh MP, Saxena A, Sharma VP, Kalra NL. Knowledge, attitude, beliefs and practices (KABP) study related to malaria and intervention strategies in ethnic tribals of Mandla (Madhya Pradesh). Curr. Scie. 1998;75:1386-90.

20.

World Health Organization, a global strategy for malaria control. Geneva: WHO 1993.

21. Oberlander L, Elverdan B. Malaria in the United Republic of Tanzania: cultural consideration and behaviour. Bull. WHO 2000;78:1352-7.

22. Adera TD. Beliefs and traditional treatment of malaria in Kishe settlement area, southwest Ethiopia. Ethiop. Med. J. 2003;41:25-34.

23.

Pilkington H, Mayombo J, Aubouy N, Deloron P. Malaria, from natural to supernatural: a qualitative study of mothers' reactions to fever (Dienga, Gabon). J. Epidemiol. Communit. Health 2004;58: 826-30. 